\title{
Behavioral and Psychological Symptoms of Dementia and Antipsychotic Drug Use in the Elderly with Dementia in Korean Long-Term Care Facilities
}

\author{
Kang Soo Lee ${ }^{1} \cdot$ Sang-Hwan Kim ${ }^{2} \cdot$ Hee-Jin Hwang ${ }^{3}$
}

Published online: 25 November 2015

(C) The Author(s) 2015. This article is published with open access at Springerlink.com

\begin{abstract}
Background Behavioral and psychological symptoms of dementia (BPSD) are known predictors of institutionalization, lower quality of life, and caregiver distress. Guidelines recommend initial management with nonpharmacological means, but antipsychotic drugs are widely used for the treatment of certain BPSD.

Objectives The objective of the current study is to analyze the prevalence of BPSD and antipsychotic drug use in long-term care facilities in Korea.

Methods Retrospective chart review and cross-sectional analysis was conducted with 529 residents diagnosed with dementia out of a total 835 residents in 20 long-term care facilities from October 2011 to April 2012. Basic characteristics of residents such as prevalence of BPSD and antipsychotic prescriptions were analyzed. BPSD was determined using the Neuropsychiatric Inventory-Questionnaire (NPI-Q) assessment tool, and associations with the use of antipsychotic drugs were investigated.

Results The mean age of the 529 residents was $81.16 \pm 8.73$ years; $410(77.5 \%)$ were female. The mean length of stay in long-term care facilities was $24.19 \pm 23.06$ months. The primary outcome was a
\end{abstract}

K. S. Lee and S.-H. Kim contributed equally as co-first authors.

Hee-Jin Hwang

ydsfm3624@ naver.com

1 Department of Psychiatry, CHA University College of Medicine, Bundang CHA Hospital, Bundang, Korea

2 Yonsei Woori Getiatric Hospital, Goyang, Korea

3 Department of Family Medicine, International St. Mary's Hospital, Catholic Kwandong University College of Medicine, 25, Simgok-ro 100beon-gil, Seo-gu, Incheon 404-834, Korea prescription rate of antipsychotic medications. Of the 529 dementia residents, $143(27 \%)$ were prescribed antipsychotic medications (quetiapine, risperidone, and olanzapine). Agitation was the most common symptom of BPSD. Disinhibition and irritability were associated with the use of antipsychotics in a multiple logistic regression analysis [respectively $P=0.007$ and 0.016 and adjusted odds ratio $($ range $)=0.51(0.31-0.83)$ and $0.57(0.36-0.90)]$.

Conclusion BPSD are common in long-term care facilities in Korea. Twenty-seven percent of dementia residents in long-term care facilities in Korea were prescribed antipsychotic medications. Furthermore, antipsychotic drug use was significantly associated with disinhibition and irritability in those patients.

\section{Introduction}

Behavioral and psychological symptoms of dementia (BPSD) are known predictors of institutionalization [1-3], lower quality of life [4], and caregiver distress [5, 6]. Guidelines recommend initial management with nonpharmacological means [7], but antipsychotic drugs are widely used for the treatment of certain BPSD. One study showed that $40 \%$ of elderly people with cognitive impairment in nursing homes took antipsychotic drugs [8]. The widespread use of antipsychotic drugs in nursing homes has been a concern for many years. Safety data from randomized clinical trials and observational studies have led regulatory agencies to issue official warnings on a possible increased risk of ischemic cerebrovascular events and all-cause death associated with the use of antipsychotics $[9,10]$. Despite US Food and Drug Administration (FDA) safety warnings, there has been little change in the rate of antipsychotic prescription in US nursing homes over 
the past decade [11-15]. On the other hand, there have been updates regarding the off-label use of atypical antipsychotics for BPSD [16], such as the comparative effectiveness reviews issued by the Agency for Healthcare Research and Quality in the USA [17]. There were small but statistically significant benefits from using aripiprazole, olanzapine, and risperidone compared with placebo in the treatment of BPSD [17]. Although the use of antipsychotics in BPSD is off-label, antipsychotics are still the best pharmacological short-term treatment option for BPSDrelated aggression/agitation [16].

There is wide variation across Organization for Economic Co-operation and Development (OECD) countries in the provision of formal long-term care (LTC) services for the elderly. A common concern has been the quality of formal LTC services, particularly in nursing homes [18, 19]. Nursing homes, themselves, involve a heterogeneous range of resident cases and services rendered, often based on country and setting [20]. The use of antipsychotics is considered an indicator of quality of care in nursing homes. Though nursing homes play an important role in providing care for the elderly, no data are currently available on the use of psychoactive medications in Korea nursing homes.

The aim of this study was to describe the pattern of use of antipsychotic drugs in Korean nursing home residents with dementia and to identify individual sociodemographic and clinical characteristics and facility-related factors that are associated with their use.

\section{Methods}

The sample data for this retrospective, cross-sectional analysis was derived from the Long-term care of Old people Via KorEan nursing home network (LOVE) study, conducted in 20 Korean LTC facilities from October 2011 to April 2012. A total of 835 residents were recruited from 20 nursing homes. Of these, 41 patients were excluded due to incomplete data and 265 patients due to no diagnosis of dementia. The study was approved by the Ethics Review Board at Myoung-Ji Hospital.

Comprehensive assessment, including medical, psychosocial, and functional evaluation, was performed by a geriatrics team [21]. The following variables were included in the analysis: gender, age (years), grade of long-term care (Grade $1=$ greater dependency and the requirement for high-level care), and history of co-morbidities such as hypertension, stroke, diabetes mellitus, osteoporosis, Parkinson's disease, and congestive heart failure. All medical diagnoses, including dementia, were made by the physicians in charge of the resident, following the usual International Classification of Diseases diagnostic criteria.
BPSD was determined using the Neuropsychiatric Inventory-Questionnaire (NPI-Q) assessment tool, and associations with the use of antipsychotic drugs were investigated. The NPI Questionnaire is a validated caregiver-completed questionnaire derived from the original NPI. The NPI-Q is used to measure 12 categories of behavioral disturbance: delusions, hallucinations, anxiety, depression/dysphoria, agitation/aggression, elation/euphoria, disinhibition, irritability/lability, apathy/Indifference, motor disturbance, night-time behavior problems, and problems with appetite/

Table 1 Demographic and baseline characteristics of nursing home residents with dementia

\begin{tabular}{|c|c|}
\hline Characteristics & $n(\%)$ \\
\hline \multicolumn{2}{|l|}{ Demographic characteristics } \\
\hline Age (mean $\pm \mathrm{SD})$, years & $81.16 \pm 8.73$ \\
\hline \multicolumn{2}{|l|}{ Sex } \\
\hline Male & $119(22.5)$ \\
\hline Female & $410(77.5)$ \\
\hline \multicolumn{2}{|l|}{ Resident characteristics } \\
\hline \multicolumn{2}{|l|}{ Grade of long-term care } \\
\hline 1 & $69(13)$ \\
\hline 2 & 167 (31.6) \\
\hline 3 & $293(55.4)$ \\
\hline Length of stay (mean $\pm \mathrm{SD}$ ), months & $24.19 \pm 23.06$ \\
\hline \multicolumn{2}{|l|}{ Clinical problems } \\
\hline Hypertension & $343(64.8)$ \\
\hline Stroke & $167(31.6)$ \\
\hline Diabetes mellitus & $134(25.3)$ \\
\hline Osteoarthritis & $84(15.9)$ \\
\hline Osteoporosis & $66(12.5)$ \\
\hline Parkinson's disease & $34(6.4)$ \\
\hline Heart failure & $12(2.3)$ \\
\hline \multicolumn{2}{|l|}{ Medications } \\
\hline Antipsychotics (N05A) & $143(27.0)$ \\
\hline Quetiapine (N05AH04) & $120(22.7)$ \\
\hline Risperidone (N05AX08) & $25(4.7)$ \\
\hline Olanzapine (N05AH03) & $21(4.0)$ \\
\hline More than two drugs & $23(4.3)$ \\
\hline \multicolumn{2}{|l|}{ Anti-dementia drugs (N06D) } \\
\hline Donepezil (N06DA02) & $97(18.3)$ \\
\hline Memantine (N06DX01) & $30(5.7)$ \\
\hline Other & $10(1.9)$ \\
\hline \multicolumn{2}{|l|}{ Antidepressants (N06A) } \\
\hline Selective serotonin reuptake inhibitor (N06AB) & $14(2.6)$ \\
\hline Trazodone (N06AX05) & $27(5.1)$ \\
\hline Tricyclic antidepressant (N06AA) & $10(1.9)$ \\
\hline Other & $10(1.9)$ \\
\hline Anticonvulsants (N03A) & $24(4.5)$ \\
\hline Anxiolytics (N05BA) & $22(4.2)$ \\
\hline
\end{tabular}

Grade 1 greater dependency and the requirement for high-level care 
Table 2 Prevalence of behavioral and psychological symptoms of dementia (BPSD) stratified by antipsychotic drug use

\begin{tabular}{|c|c|c|c|}
\hline BPSD & No antipsychotic medication, $n=386(\%)^{\mathrm{a}}$ & Antipsychotic medication, ${ }^{(\mathrm{b})} n=143(\%)^{(\mathrm{a})}$ & $P$ value $^{\mathrm{c}}$ \\
\hline Delusions & $142(36.8)$ & $45(31.5)$ & 0.256 \\
\hline Severity & $2.11 \pm 0.76$ & $2.13 \pm 0.84$ & 0.836 \\
\hline Distress & $2.8 \pm 1.36$ & $2.73 \pm 1.44$ & 0.790 \\
\hline Hallucinations & $104(26.9)$ & $44(30.8)$ & 0.384 \\
\hline Severity & $2.25 \pm 0.79$ & $2.27 \pm 0.76$ & 0.859 \\
\hline Distress & $2.81 \pm 1.47$ & $3.11 \pm 1.47$ & 0.250 \\
\hline Agitation & $205(53.1)$ & $66(46.2)$ & 0.155 \\
\hline Severity & $2.27 \pm 0.79$ & $2.30 \pm 0.84$ & 0.788 \\
\hline Distress & $2.98 \pm 1.40$ & $3.04 \pm 1.57$ & 0.749 \\
\hline Depression & 199 (51.6) & $75(52.4)$ & 0.855 \\
\hline Severity & $2.06 \pm 0.75$ & $1.93 \pm 0.83$ & 0.226 \\
\hline Distress & $2.41 \pm 1.32$ & $2.21 \pm 1.34$ & 0.281 \\
\hline Anxiety & 107 (27.7) & $40(28.0)$ & 0.954 \\
\hline Severity & $1.99 \pm 0.81$ & $1.95 \pm 0.75$ & 0.782 \\
\hline Distress & $2.36 \pm 1.45$ & $2.45 \pm 1.40$ & 0.720 \\
\hline Euphoria & 99 (25.6) & $36(25.2)$ & 0.912 \\
\hline Severity & $1.87 \pm 0.65$ & $1.97 \pm 0.77$ & 0.438 \\
\hline Distress & $1.99 \pm 1.27$ & $1.83 \pm 1.48$ & 0.545 \\
\hline Apathy & $137(35.5)$ & $46(32.2)$ & 0.475 \\
\hline Severity & $2.66 \pm 0.73$ & $2.00 \pm 0.82$ & 0.047 \\
\hline Distress & $2.64 \pm 1.38$ & $2.07 \pm 1.22$ & 0.012 \\
\hline Disinhibition & $155(40.2)$ & $36(25.2)$ & 0.001 \\
\hline Severity & $2.23 \pm 0.75$ & $2.39 \pm 0.65$ & 0.246 \\
\hline Distress & $2.93 \pm 1.46$ & $3.06 \pm 1.41$ & 0.637 \\
\hline Irritability & $178(46.1)$ & 48 (33.6) & 0.010 \\
\hline Severity & $2.18 \pm 0.80$ & $2.38 \pm 0.76$ & 0.130 \\
\hline Distress & $2.79 \pm 1.43$ & $2.90 \pm 1.42$ & 0.656 \\
\hline Aberrant motor behavior & $123(31.9)$ & $43(30.1)$ & 0.693 \\
\hline Severity & $2.30 \pm 0.75$ & $2.42 \pm 0.63$ & 0.355 \\
\hline Distress & $3.11 \pm 1.39$ & $2.72 \pm 1.32$ & 0.115 \\
\hline Night-time behavior & $155(40.2)$ & $52(36.4)$ & 0.427 \\
\hline Severity & $2.25 \pm 0.74$ & $2.35 \pm 0.62$ & 0.406 \\
\hline Distress & $3.05 \pm 1.39$ & $2.75 \pm 1.33$ & 0.182 \\
\hline Appetite/eating behavior & $73(18.9)$ & $18(12.6)$ & 0.087 \\
\hline Severity & $2.01 \pm 0.74$ & $1.94 \pm 0.80$ & 0.726 \\
\hline Distress & $2.21 \pm 1.35$ & $1.89 \pm 1.57$ & 0.391 \\
\hline
\end{tabular}

${ }^{\text {a }}$ Values are presented as $n(\%)$ for prevalence of BPSD, mean \pm SD for severity and distress

${ }^{\mathrm{b}}$ Prescribed antipsychotic medications were quetapine, risperidone, and olanzapine

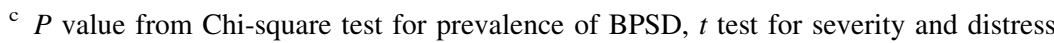

eating. The questionnaire is completed by a caregiver and determines whether the patient exhibits each of the behaviors [22]. Drugs were classified according to the Anatomical Therapeutic Chemical (ATC) classification system [23]. Psychotropic drugs were categorized as follows: any psychotropic (ATC-codes N05 and N06), antipsychotics (N05A), anxiolytics (N05B), hypnotics (N05C), and antidepressants (N06A).
Resident baseline characteristics were described using $t$ tests for continuous variables and Chi-square tests for categorical variables. NPI-Q characteristics were described according to the use of antipsychotic drugs, and differences in these characteristics were identified by Chi-square tests. To examine factors associated with antipsychotic drug use, multiple logistic regression analysis was performed. The dependent variable was the antipsychotic drug use, and the 
Table 3 Prevalence of antipsychotic use in dementia patients stratified by anti-dementia drug use

\begin{tabular}{lcccc}
\hline & Donepezil (N06DA02) & Memantine (N06DX01) & Other drugs & No antidementia drug use \\
\hline Quetiapine (N05AH04) & $31(25.8)$ & $16(13.3)$ & $6(5.0)$ & $67(55.8)$ \\
Risperidone (N05AX08) & $6(24.0)$ & $3(12.0)$ & $2(8.0)$ & $14(56.0)$ \\
Olanzapine (N05AH03) & $7(33.3)$ & $5(23.8)$ & 0 & $9(42.9)$ \\
\hline
\end{tabular}

Values are presented as $n(\%)$

Table 4 Logistic regression analysis for antipsychotic use in long-term care facility residents with dementia

\begin{tabular}{lrlll}
\hline BPSD $^{\mathrm{a}}$ & \multicolumn{1}{l}{$\beta$} & Standard error & $P$ value & Adjusted $\mathrm{OR}^{\mathrm{b}}\left(95 \% \mathrm{CI}^{\mathrm{c}}\right)$ \\
\hline Delusions & -0.254 & 0.238 & 0.286 & $0.78(0.48-1.24)$ \\
Hallucinations & 0.287 & 0.244 & 0.239 & $1.33(0.83-2.15)$ \\
Agitation & -0.106 & 0.225 & 0.637 & $0.90(0.58-1.40)$ \\
Depression & 0.167 & 0.225 & 0.457 & $1.18(0.76-1.83)$ \\
Anxiety & -0.760 & 0.252 & 0.763 & $0.93(0.57-1.52)$ \\
Euphoria & 0.229 & 0.253 & 0.364 & $1.26(0.77-2.07)$ \\
Apathy & 0.044 & 0.235 & 0.850 & $1.05(0.66-1.66)$ \\
Disinhibition & -0.673 & 0.247 & 0.007 & $0.51(0.31-0.83)$ \\
Irritability & -0.563 & 0.233 & 0.016 & $0.57(0.36-0.90)$ \\
Aberrant motor behavior & -0.045 & 0.242 & 0.854 & $0.96(0.60-1.54)$ \\
Night-time behavior & -0.152 & 0.230 & 0.508 & $0.86(0.55-1.35)$ \\
Appetite/eating behavior & -0.572 & 0.328 & 0.081 & $0.56(0.30-1.07)$
\end{tabular}

Adjusted for age, sex, grade of long term care, and length of stay

${ }^{\text {a }}$ Behavioral and psychological symptoms of dementia

b Odds ratio

c Confidence interval independent predictors were age, sex, the grade of longterm care, the length of stay, and other drugs. All analyses were conducted using SPSS 18.0 software for Windows.

\section{Results}

Table 1 shows the baseline characteristics of residents with dementia. The mean age of the total 529 dementia residents was $81.16 \pm 8.73$ years (mean \pm SD), and $410(77.5 \%)$ of the residents were female. The average length of stay in long-term care facilities was $24.19 \pm 23.06$ months. In the $143(27 \%)$ residents currently using antipsychotics [quetiapine (N05AH04), risperidone (N05AX08), and olanzapine (N05AH03)], the most commonly prescribed medication in these residents; $25.9 \%$ were taking an antidementia drug [donepezil (N06DA02), memantine (N06DX01), and other].

Tricyclic antidepressants, which are inappropriate in dementia because of anticholinergic vulnerability, were prescribed in $10(1.9 \%)$ residents. Agitation $(51.2 \%)$ was one of the most common of the behavioural and psychological symptoms of dementia (see Table 2). Of the residents taking an anti-dementia drug, $69.7 \%$ were taking quetiapine, $14.5 \%$ risperidone, and $15.8 \%$ olanzapine (Table 3). Disinhibition and irritability were associated with the use of antipsychotics in a multiple logistic regression analysis. Indeed, the multiple logistic regression analysis showed that those who exhibited disinhibition and irritability were at increased risk of being prescribed an antipsychotic drug (Table 4).

\section{Discussion}

A diagnosis of dementia was present in $63.3 \%$ of 835 residents in 20 long-term care facilities in Korea, and $27.0 \%$ of these residents had been prescribed an antipsychotic drug. A previous study showed that of 1334 nonagenarian residents in long-term care, $30 \%$ has been prescribed an antipsychotic medication [24]. In 2005, HosiaRandell and Pitkälä [25] stated that $31.3 \%$ of non-agenarian residents in nursing homes in Helsinki were taking antipsychotics. The present results are also in agreement with the earlier findings of studies by Oborne (24.5\%) [26] and Briesacher (27.6 \%) [12].

A number of limitations must be mentioned with regard to the present study. First, the study was cross-sectional, 
thus providing a comprehensive snapshot at one point in time but without the ability to establish causal relationships. Second, the facilities included in the study were not randomly selected. As such, they may not be nationally representative or generalizable to all long-term care residents in Korea. There is also a possibility of selection bias as geriatricians may have a tendency to prescribe antipsychotic drugs or that patients with more severe BSPD are primarily admitted to facilities in which such a geriatrician was known to be available. Nevertheless, the strengths of this work should not be overlooked. The study included a relatively large sample to illustrate current antipsychotic use in Korean nursing homes.

Behavioral symptoms and dementia have previously been shown to be the main predictors of antipsychotic prescriptions in nursing home residents $[27,28]$ and the results of our study support this finding. Continuous prescription of antipsychotics here and in another study [29] is not concordant with current treatment recommendations, and the need for continued treatment should be reviewed regularly every 6 months [30-32]. On the other hand, antipsychotics showed small but statistically significant benefits in the treatment of BPSD and are still the short-term pharmacological treatment option for BPSD associated with disinhibition and irritability in long-term care facilities in Korea.

\section{Conclusion}

BPSD are common in long-term care facilities in Korea. Twenty-seven percent of dementia residents in long-term care facilities in Korea were prescribed antipsychotic medications. Furthermore, antipsychotic drug use was significantly associated with disinhibition and irritability in those patients.

\section{Compliance with Ethical Standards}

Funding Kang Soo Lee, Sang-Hwan Kim, and Hee-Jin Hwang confirm that no funding was received for the conduct of the study and/ or preparation of the manuscript.

Conflict of interest Kang Soo Lee, Sang-Hwan Kim, and Hee-Jin Hwang have no conflicts of interest to declare.

Ethical approval This study was approved by the Ethics Review Board of Myoung-Ji Hospital and was performed in accordance with the ethical standards of the declaration of Helsinki.

Open Access This article is distributed under the terms of the Creative Commons Attribution-NonCommercial 4.0 International License (http://creativecommons.org/licenses/by-nc/4.0/), which permits any noncommercial use, distribution, and reproduction in any medium, provided you give appropriate credit to the original author(s) and the source, provide a link to the Creative Commons license, and indicate if changes were made.

\section{References}

1. O’Donnell BF, Drachman DA, Barnes HJ, et al. Incontinence and troublesome behaviors predict institutionalization in dementia. J Geriatr Psychiatry Neurol. 1992;5:45-52.

2. Steele C, Rovner B, Chase GA, et al. Psychiatric symptoms and nursing home placement of patients with Alzheimer's disease. Am J Psychiatry. 1990;147:1049-51.

3. De Vugt ME, Stevens F, Aalten P, et al. A prospective study of the effects of behavioral symptoms on the institutionalization of patients with dementia. Int Psychogeriatr. 2005;17:577-89.

4. Ryu SH, Ha JH, Park DH, et al. Persistence of neuropsychiatric symptoms over six months in mild cognitive impairment in community-dwelling Korean elderly. Int Psychogeriatr. 2011;23:214-20.

5. Tan LL, Wong HB, Allen H. The impact of neuropsychiatric symptoms of dementia on distress in family and professional caregivers in Singapore. Int Psychogeriatr. 2005;17:253-63.

6. Huang SS, Lee MC, Liao YC, et al. Caregiver burden associated with behavioral and psychological symptoms of dementia (BPSD) in Taiwanese elderly. Arch Gerontol Geriatr. 2012;55: $55-9$.

7. Hermann N. Recommendations for the management of behavioural and psychological symptoms of dementia. Can J Neuro Sci. 2001;28:96-107.

8. Lövheim H, Sandman PO, Kallin K, Karlsson S, Gustafson Y. Relationship between antipsychotic drug use and behavioral and psychological symptoms of dementia in old people with cognitive impairment living in geriatric care. Int Psychogeriatr. 2006;18: 713-26.

9. Food and Drug Agency. Public Health Advisory: Deaths with antipsychotics in elderly patients with behavioural disturbances. Silver Spring (MD): US Food andDrug Administration. 2005. http://www.fda.gov/Safety/MedWatch/SafetyInformation/Safety AlertsforHumanMedicalProducts/ucm150688.htm. Accessed 22 Jun 2015.

10. European Medicines Agency. CHMP Assessment Report on Conventional Antipsychotics. EMA. 2008. http://www.ema. europa.eu/docs/en_GB/document_library/Other/2012/05/WC5001 27477.pdf. Accessed 22 Jun 2015.

11. Liperoti R, Mor V, Lapane KL, et al. The use of atypical antipsychotics in nursing homes. J Clin Psychiatry. 2003;64: 1106-12.

12. Briesacher BA, Limcangco MR, Simoni-Wastila L, et al. The quality of antipsychotic drug prescribing in nursing homes. Arch Intern Med. 2005;165:1280-5.

13. Bronskill SE, Anderson GM, Sykora K, et al. Neuroleptic drug therapy in older adults newly admitted to nursing homes: incidence, dose and specialist contact. J Am Geriatr Soc. 2004;52:749-55.

14. Rochon PA, Stukel TA, Bronskill SE, et al. Variation in nursing home antipsychotic prescription rates. Arch Intern Med. 2007;167:676-83.

15. Chen Y, Briesacher B, Field T, et al. Unexplained variation across US nursing homes in antipsychotic prescribing rates. Arch Intern Med. 2010;170:89-95.

16. Azermai M. Dealing with behavioral and psychological symptoms of dementia: a general overview. Psychol Res Behav Manag. 2015;8:181-5.

17. Agency for Healthcare Research and Quality. Off-label use of atypical antipsychotics: an update. No 43. Rockville, MD, USA: comparative effectiveness reviews; 2011. http://www.ncbi.nlm. nih.gov/books/NBK66081/. Accessed 7 Sep 2015.

18. OECD. Policy brief. Ensuring quality long-term care for older people. Paris: OECD; 2005. http://www.oecd.org/els/healthsystems/Ensuring-quality-long-term-care-for-older-people.pdf. Accessed 22 Jun 2015. 
19. Wiener JM, Tilly J, Howe A, et al. Quality assurance for longterm care: the experiences of England, Australia, Germany and Japan. Washington, DC: AARP; 2007.

20. Ribbe MW, Ljunggren G, Steel K, et al. Nursing homes in 10 nations: a comparison between countries and settings. Age Ageing. 1997;26(Suppl 2):3-12.

21. Jung Sun-Young, Kwon In Soon, Cho BeLong, Yoon Jong Lull, Rho Yong Gyun, Lee Eunju, et al. Reliability and Validity of Korean brief comprehensive geriatric assessment questionnaire. J Korean Geriatr So. 2006;10(2):67-76.

22. Kaufer DI, Cummings JL, Ketchel P, Smith V, MacMillan A, Shelley T, et al. Validation of the NPI-Q, a brief clinical form of the Neuropsychiatric Inventory. J Neuropsychiatry Clin Neurosci. 2000;12(2):233-9.

23. WHO Collaborating Centre for drug statistics methodology: ATC index with DDDs. [http://www.whocc.no]. Accessed 22 Jun 2015.

24. Alanen HM, Finne-Soveri H, Noro A, Leinonen E. Use of antipsychotics among nonagenarian residents in long-term institutional care in Finland. Age Ageing. 2006;35(5):508-13.

25. Hosia-Randell H, Pitkälä K. Use of psychotropic drugs in elderly nursing home residents with and without dementia in Helsinki, Finland. Drugs Aging. 2005;22(9):793-800.
26. Oborne CA, Hooper R, Li KC, et al. An indicator of appropriate neuroleptic prescribing in nursing homes. Age Ageing. 2002;31:435-9.

27. Nishtala PS, McLachlan AJ, Bell JS, Chen TF. Determinants of antipsychotic medication use among older people living in aged care homes in Australia. Int J Geriatr Psychiatry. 2010;25(5):449-57.

28. Macdonald AJ, Carpenter GI, Box O, Roberts A, Sahu S. Dementia and use of psychotropic medication in non-"Elderly Mentally Infirm" nursing homes in South East England. Age Ageing. 2002;31(1):58-64.

29. Nobili A, Pasina L, Trevisan S, Riva E, Lucca U, Tettamanti M, et al. Use and misuse of antipsychotic drugs in patients with dementia in Alzheimer special care units. Int Clin Psychopharmacol. 2009;24(2):97-104.

30. Alexopoulos GS, Streim J, Carpenter D, Docherty JP. Using antipsychotic agents in older patients. J Clin Psychiatry. 2004;65(Suppl 2):5-99 (discussion 100-102; quiz 103-4).

31. Ballard C, Creese B, Corbett A, Aarsland D. Atypical antipsychotics for the treatment of behavioral and psychological symptoms in dementia, with a particular focus on longer term outcomes and mortality. Expert Opin Drug Saf. 2011;10:35-43.

32. Ballard C, Howard R. Neuroleptic drugs in dementia: benefits and harm. Nat Rev Neurosci. 2006;7(6):492-500. 